NEWS

\title{
China builds inland Antarctic base
}

\section{Kunlun station to open later this month atop the frozen continent's oldest ice.}

After a three-week crawl carrying 625 tonnes of cargo towards the highest ice in Antarctica, a Chinese expedition is expected this week to begin building a research base at Dome Argus, or 'Dome A', 4,093 metres above sea level. The station, called Kunlun and scheduled to open on 28 January, will gather data in fields ranging from global climate change to the origin of the Universe.

The 250-million-renminbi (US\$37-million) Kunlun will be China's third Antarctic station, joining the Great Wall station in the South Shetland Islands and the Zhongshan station in east Antarctica. "The Kunlun station will be a major legacy of the International Polar Year and will propel China to the heart of the Antarctic map," says Jean de Pomereu, a photographer who followed the expedition to Zhongshan for the Brussels-based International Polar Foundation. "It is absolutely fantastic to have a station there," adds Eric Wolff, an ice-core specialist at the British Antarctic Survey in Cambridge, UK.

On 20 October, the Chinese Arctic and Antarctic Administration (CAA) sent its expedition team from Shanghai aboard the icebreaker Xue Long ('Snow Dragon' in English) to the coastal Zhongshan station.

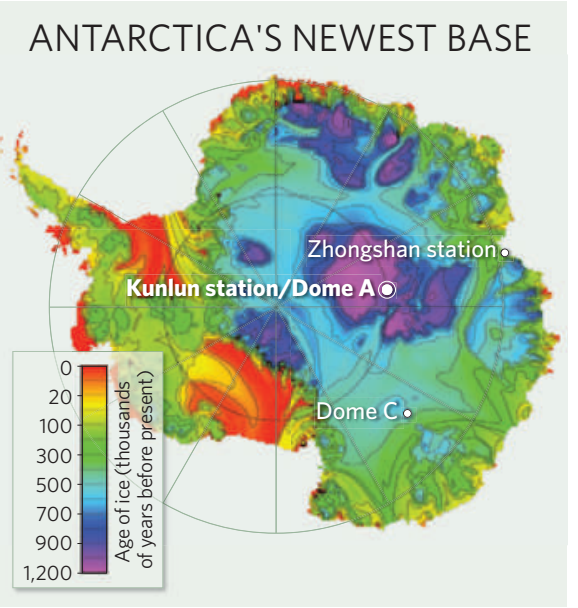

Bad ice conditions delayed their arrival, but on 18 December - two weeks behind schedule - a 28-man 'inland team' began the nearly 1,300-kilometre traverse to Dome A. On arriving at Dome A this week, the expeditioners will have just 20 days to build the station before temperatures drop sharply to below $-50{ }^{\circ} \mathrm{C}$ in early February.

At the end of this year's first phase of construction, Kunlun is expected to have a main building of 230 square metres, with 11 units for sleeping, eating and working. It will have space for up to 25 people, says Qu Tanzhou, director of the CAA. Six more units are expected to be added next year, for a total area of 327 square metres.

Over the next decade, China hopes to add more facilities to Kunlun, including a large fuel tank and a solar-panel array to provide additional power, and to eventually be able to operate year round. The CAA also plans to have its own aircraft in Antarctica to shuttle researchers between Zhongshan and Kunlun, increasing the research capacity at both o stations. "Only with these logistics in place will we be able to make the most out of the station," says Qu.

A key focus of research is finding sites where ice cores stretching back further in time than any others could be drilled. A core obtained at a site known as Dome C - about 1,000 kilometres from Dome A (see map) - reached 3,200 metres deep and helped to reconstruct past climate going back 800,000 years. Many believe that Dome A promises older ice because it is higher and has less snow, meaning that researchers can get more years of climate records in a given thickness of ice.

"Our radar studies show that the ice

\section{Companies racing into India's nuclear market}

Russia, France and other countries are rushing to capitalize on India's nuclear-power programme, four months after the United States pressured the 45-nation Nuclear Suppliers Group to end India's nuclear isolation. Arms-control experts strongly criticize the Indo-US nuclear deal that set off the rush, saying it undermines the Nuclear Non-Proliferation Treaty. India, a nuclear-armed state, has not signed the treaty; those seeking to sell to it have.

India wants to increase the proportion of its electricity generated from nuclear sources from $2.8 \%$ to $25 \%$ by 2050 . That would mean building 30 or more new reactors to join the 17 existing ones and the 6 that are under construction.
The Nuclear Power Corporation of India Limited (NPCIL) in Mumbai expects this month to finalize a total of US $\$ 15$ billion in contracts with France's Areva group and Russia's nuclear-energy conglomerate Rosatom, says NPCIL chairman Shreyans Kumar Jain. The US companies Westinghouse and General Electric have not signed contracts, but are due this month to visit India and scout out possible locations for reactors. The NPCIL has readied four sites - one for each vendor - each capable of accepting eight to ten imported reactors.

On 5 December, Russian president Dmitry Medvedev signed a deal in New Delhi that paves the way for four more 1-gigawatt reactors over the next decade, in addition to the two that Russia is already building at Kudankulam in the southern state of Tamil Nadu. In November, the United Kingdom lifted its six-yearold blanket ban on exporting 'trigger list' items, including nuclear materials, to India. And in September, France signed an agreement similar to the US one to share nuclear technology and know-how with India.

Some formalities remain before the US and French agreements can be declared operational, says Ravi Bhushan Grover, director of strategic planning in India's Department of Atomic Energy (DAE) and a key negotiator of the Indo-US

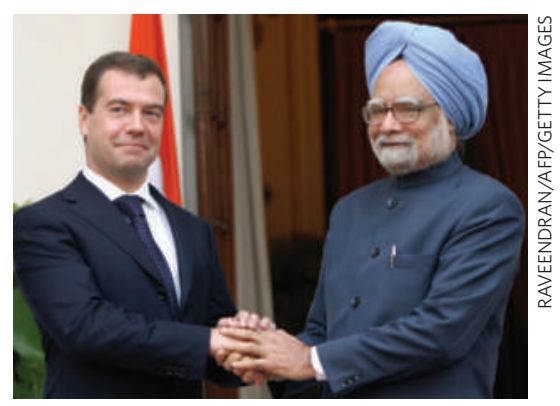

Russian President Dmitry Medvedev and Indian Prime Minister Manmohan Singh.

nuclear deal. The countries will have to exchange diplomatic notes confirming that all requirements have been met. The DAE must also file a declaration with the International Atomic Energy Agency (IAEA) listing civilian facilities to 


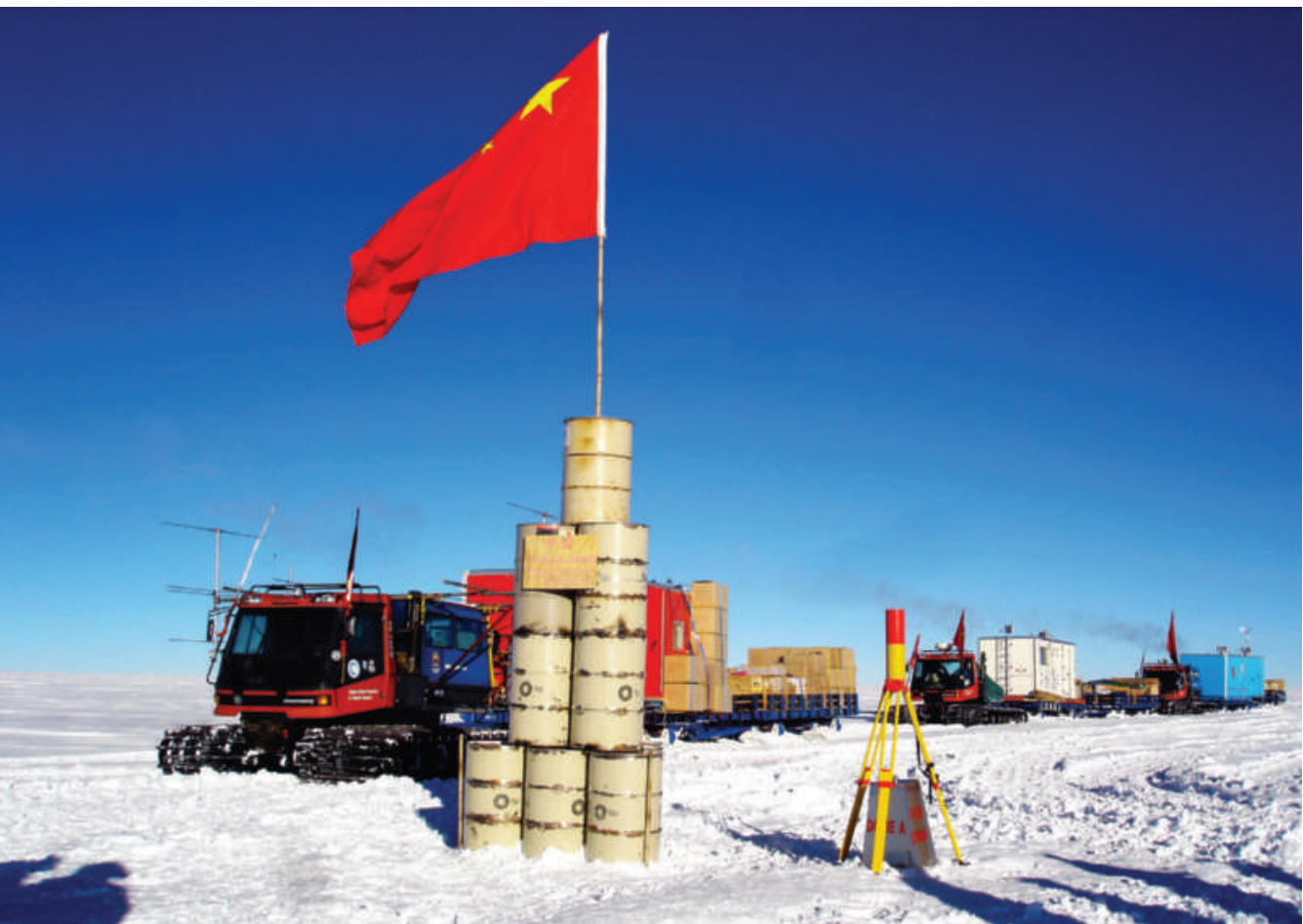

A base at Antarctica's Dome A could provide access to the oldest ice-core samples yet.

underneath Dome A is over 3,000 metres thick," says Sun Bo, a glaciologist at the Polar Research Institute of China, based in Shanghai. "This could push the climate record back to 1.5 million years."

What ice-core researchers have to decide first is where exactly to place their drills. "Ideally, the ice has to be deep and unfolded and not melting at the bottom," says Sun. To locate such ice, they are looking for help from Antarctica's Gamburtsev Province Project, an international initiative that is collecting data over a vast area of east Antarctica, including the buried Gamburtsev mountain range.

For the past several weeks, low-flying aircraft have been sweeping over the area, gathering gravity and magnetic readings as well as radar information to illuminate the thickness and internal layers of the ice sheet. The group has made at least seven data flights over Dome A, which will be fed into ice models to predict the best places to drill a core. Meanwhile, the Polar Research Institute of China will continue to gather data from the ground and will start test-drilling as early as next year.

Until then, researchers are pursuing other work they can do at Dome A: astronomical observing. "The seeing conditions on Dome A are just phenomenal," says Cui Xiangqun, director of the Nanjing Institute of Astronomical Optics \& Technology. Last year the Chinese team installed a remotely operated observatory called PLATO built by the University of New South Wales in Sydney, Australia. Two of its four 14.5-centimetre optical telescopes broke down halfway through the winter, whereas the other two operated for more than 130 days before the last engine gave out. Early results from another PLATO telescope suggest that Dome A is an excellent spot to observe at sub-millimetre wavelengths.

Gong Xuefei, of the Nanjing institute, will repair parts of PLATO and calibrate its instruments this month - as well as adding an instrument to measure the transparency of the sky. Jane Qiu be placed under its safeguards; as part of the US deal, India agreed to separate civilian nuclear facilities from military ones and open to IAEA inspectors its present and future civilian facilities.

That is far from sufficient, say arms-control experts who argue that India should sign and ratify the Comprehensive Nuclear-Test-Ban Treaty, as well as cap the amount of fissile weapons material it produces. "India retains, deal or no deal, the capability to produce weapons-grade material at a far higher rate than it is believed to have ever done or to be likely to do," says Paul Nelson at the Nuclear Security Science and Policy Institute of Texas A\&M University in College Station. The United States unilaterally brought India in from the nuclear cold without requiring it to make significant concessions, says Rebecca Johnson, director of the Acronym Institute for Disarmament Diplomacy in London.

Within India, DAE employees are concerned that an influx of proposed new reactors could lead to quality standards being compromised. The country's Atomic Energy Regulatory Board will have to inspect and clear several new reactors of different designs as they are approved. "Our primary concern is over safety," says A. Sathasivam, president of the National Federation of Atomic Energy Employees. Om Pal Singh, the board's secretary, says the problem is simply a lack of manpower. To deal with the new applications, the board intends to double its number of regulators within the next five years, he says.

And the NPCIL is losing staff, because many of its employees have been enticed into more lucrative jobs as consultants in the new nuclear rush. "Almost all our directors who have retired or who are going to retire in a few years have been grabbed by private companies at ten times my salary," says Jain. For instance, his predecessor, V. K. Chaturvedi, now heads the nuclear group at Reliance Infrastructure in Mumbai, and some present and former NPCIL engineers are in the process of forming nuclear-consultancy companies.

Meanwhile, domestic critics such as Annaswamy Narayana Prasad retired director of the Bhabha Atomic Research Centre, and Padmanabha Krishnagopala lyengar, former DAE secretary, claim that Indian nuclear scientists are giving up prematurely on their thorium research programme in exchange for a few uranium reactors from abroad. India has very little domestic uranium but one-quarter of the world's thorium reserves; its thorium research programme focuses on turning the material into fissile uranium-233 for use as reactor fuel. Fast breeder reactors, of the type under construction in Kalpakkam, would breed uranium-233 in thorium blankets surrounding a plutonium core. Recovering plutonium and uranium-233 from spent fuel is key to India's thorium programme, but, under the Indo-US deal, this has to be done in a dedicated plant under IAEA safeguards and with US permission.

Still, at least one overseas company is betting on thorium. Last month, Thorium Power in McLean, Virginia, with a market capitalization of about $\$ 40$ million, established a joint venture with Punj Lloyd, an engineering company in Gurgaon. The two companies plan to set up an investment fund and to act as consultants to other companies looking to get in on the rush. K. S. Jayaraman, with additional reporting by Declan Butler. 